British Journal of Nutrition (2022), 127, 896-903

(C) The Author(s), 2021. Published by Cambridge University Press on behalf of The Nutrition Society. This is an Open Access article, distributed under the terms of the Creative Commons Attribution licence (http://creativecommons.org/licenses/by/4.0/), which permits unrestricted re-use, distribution, and reproduction in any medium, provided the original work is properly cited.

\title{
Vitamin D status of children with paediatric inflammatory multisystem syndrome temporally associated with severe acute respiratory syndrome coronavirus 2 (PIMS-TS)
}

\author{
Angeline Darren ${ }^{1}$, Meissa Osman ${ }^{1}$, Kavitha Masilamani ${ }^{1}$, Syed Habib Ali ${ }^{1}$, Hari
}

Krishnan Kanthimathinathan ${ }^{2}$, Ashish Chikermane ${ }^{3}$, Eslam Al-Abadi ${ }^{4}$, Steven B. Welch ${ }^{5}$, Scott Hackett ${ }^{5}$, Barnaby R. Scholefield ${ }^{6}$, Suma Uday $^{7 \dagger}$ and Deepthi Jyothish ${ }^{1 * \dagger}$

${ }^{1}$ Department of General Paediatrics, Birmingham Women's and Children's NHS Foundation Trust, Birmingham, UK

${ }^{2}$ Paediatric Intensive Care Unit, Birmingham Women's and Children's NHS Foundation Trust, Birmingham, UK

${ }^{3}$ Department of Cardiology, Birmingham Women's and Children's NHS Foundation Trust, Birmingham, UK

${ }^{4}$ Childhood Arthritis and Rheumatic Diseases Unit, Birmingham Women's and Children's NHS Foundation Trust,

Birmingham, UK

${ }^{5}$ Department of Paediatrics, Birmingham Chest Clinic and Heartlands Hospital, University Hospitals Birmingham,

Birmingham, UK

${ }^{6}$ Birmingham Acute Care Research Group, Institute of Inflammation and Ageing, University of Birmingham, Birmingham, UK ${ }^{7}$ Department of Endocrinology and Diabetes, Birmingham Women's and Children's NHS Foundation Trust, Birmingham, UK

(Submitted 28 August 2020 - Final revision received 25 April 2021 - Accepted 3 May 2021 - First published online 12 May 2021)

\section{Abstract}

Coronavirus disease 2019 (COVID-19) has caused mild illness in children, until the emergence of the novel hyperinflammatory condition paediatric inflammatory multisystem syndrome temporally associated with severe acute respiratory syndrome coronavirus 2 (SARS-CoV-2) (PIMS-TS). PIMS-TS is thought to be a post-SARS-CoV-2 immune dysregulation with excessive inflammatory cytokine release. We studied 25 hydroxyvitamin D (25OHD) concentrations in children with PIMS-TS, admitted to a tertiary paediatric hospital in the UK, due to its postulated role in cytokine regulation and immune response. Eighteen children (median (range) age 8.9 (0.3-14.6) years, male $=10$ ) met the case definition. The majority were of Black, Asian and Minority Ethnic (BAME) origin $(89 \%, 16 / 18)$. Positive SARS-CoV-2 IgG antibodies were present in $94 \%(17 / 18)$ and RNA by PCR in $6 \%(1 / 18)$. Seventy-eight percentage of the cohort were vitamin D deficient $(<30 \mathrm{nmol} / \mathrm{l})$. The mean 25OHD concentration was significantly lower when compared with the population mean from the 2015/16 National Diet and Nutrition Survey (children aged $4-10$ years) $(24 v .54 \mathrm{nmol} / 1$ (95\% CI $-38 \cdot 6,-19 \cdot 7) ; P<0 \cdot 001)$. The paediatric intensive care unit (PICU) group had lower mean 25OHD concentrations compared with the non-PICU group, but this was not statistically significant $(19 \cdot 5 v \cdot 31 \cdot 9 \mathrm{nmol} / 1 ; P=0 \cdot 11)$. The higher susceptibility of BAME children to PIMS-TS and also vitamin D deficiency merits contemplation. Whilst any link between vitamin D deficiency and the severity of COVID-19 and related conditions including PIMS-TS requires further evidence, public health measures to improve vitamin D status of the UK BAME population have been long overdue.

Key words: Coronavirus disease 2019: Paediatric inflammatory multisystem syndrome temporally associated with severe acute respiratory syndrome coronavirus 2: Multisystem Inflammatory Syndrome in Children: Paediatric intensive care unit: Severe acute respiratory syndrome coronavirus 2: Vitamin $D$ deficiency

The coronavirus disease 2019 (COVID-19) pandemic caused by severe acute respiratory syndrome coronavirus 2 (SARS-CoV-2) has caused mild illness in the majority of children, with few severe cases requiring hospitalisation and very few deaths ${ }^{(1)}$, a finding also reflected in data from our paediatric unit ${ }^{(2)}$. However, since April 2020, there has been increasing numbers of children presenting with a hyperinflammatory condition described by the UK Royal College of Paediatrics and Child

Abbreviations: BAME, Black, Asian and Minority Ethnic; COVID-19, coronavirus disease 2019; PICU, paediatric intensive care unit; PIMS-TS, paediatric inflammatory multisystem syndrome temporally associated with severe acute respiratory syndrome coronavirus 2; SARS-CoV-2, severe acute respiratory syndrome coronavirus 2; 25OHD, 25 hydroxyvitamin D

* Corresponding author: Dr Deepthi Jyothish, email deepthi.jyothish@nhs.net

$\dagger$ These authors contributed equally as senior authors. 
Health as paediatric inflammatory multisystem syndrome temporally associated with severe acute respiratory syndrome coronavirus 2 (PIMS-TS) ${ }^{(3)}$ and as Multisystem Inflammatory Syndrome in Children associated with COVID-19 by the Centers for Disease Control $^{(4)}$ in the USA. PIMS-TS has overlapping features with other childhood inflammatory conditions such as Kawasaki disease, toxic shock syndrome and macrophage activation syndrome ${ }^{(5)}$ but remains a separate clinical entity with distinct cytokine profiles, including marked elevations in IL-6, IL-8 and IL-10. Recent studies suggest that PIMS-TS is a post-infectious hyperinflammatory syndrome with the putative cause being immune dysregulation by SARS-CoV-2, as evidenced by laboratory confirmation of preceding SARS-CoV-2 infection ${ }^{(6)}$.

The influence of 25 hydroxyvitamin D (25OHD) in PIMS-TS is proposed to be through its well-established role in the modulation of adaptive and innate immunity, including regulation of inflammatory cytokine release ${ }^{(7)}$. 25OHD down-regulates type $1 \mathrm{~T}$ cells and up-regulates type $2 \mathrm{~T}$ cells by reducing production of pro-inflammatory cytokines (IL-6, IL-8 and IL-17) and increasing anti-inflammatory cytokines (IL-10) ${ }^{(8)}$ and this immunoregulatory action is postulated to be involved in PIMS-TS.

A handful of studies have evaluated the association between 25OHD levels and COVID-19 in adults which were recently summarised in the rapid National Institute for Health and Care Excellence evidence summary ${ }^{(9)}$. To date, no studies have reported the vitamin D status of children with COVID-19 or associated conditions. We report, for the first time, the vitamin D status of children with PIMS-TS admitted to a single tertiary paediatric hospital in the Midlands region of the UK.

\section{Aims}

- Report 25OHD concentrations in children with PIMS-TS requiring hospitalisation.
- Compare mean 25OHD concentrations in children with PIMSTS to healthy paediatric population.

- Compare 25OHD concentrations and inflammatory markers in children with severe illness with circulatory shock requiring paediatric intensive care unit (PICU group) support to children who experienced a less severe disease course (nonPICU group).

\section{Methods}

\section{Study design and participants}

We undertook a single-centre observational study of children admitted to Birmingham Children's Hospital, Birmingham, UK, with PIMS-TS, between 12th April and 25th June 2020. All children who met the Royal College of Paediatrics and Child Health $^{(3)}$, Centers for Disease Control ${ }^{(4)}$, and $\mathrm{WHO}^{(10)}$ case definitions of PIMS-TS as detailed in Box 1 were included. Samples for $25 \mathrm{OHD}$ concentrations were obtained at presentation in all children as part of diagnostic bloods as per the Royal College of Paediatrics and Child Health PIMS-TS protocol.

\section{Ethics and consent}

The project was approved as service evaluation by our institution's audit committee. Additionally, all parents/legal guardians provided signed informed consent for inclusion of de-identified data in this report. Research Ethics Committee or Health Research Authority approval was not required as per the Health Research Authority assessment tool.

\section{Data collection}

Epidemiological, clinical and laboratory data on all children with PIMS-TS were gathered from clinical notes and electronic health record systems. Ethnicity details were recorded in clinical

Box 1. Case definitions of Paediatric inflammatory multisystem syndrome as per RCPCH, CDC and WHO.

RCPCH case definition (3)

1. A child or young person presenting with fever, evidence of inflammation (neutrophilia, elevated CRP and lymphopenia) with evidence of single or multi-organ failure (shock, cardiac, respiratory, renal, gastrointestinal or neurological disorder) with additional features that may include full or partial criteria for Kawasaki's disease AND

2. Exclusion of any other microbial cause, including bacterial sepsis, staphylococcal or streptococcal shock syndromes, infections associated with myocarditis such as enterovirus AND

3. SARS-CoV-2-PCR testing may be positive or negative.

CDC case definition (4)

1. An individual aged $<21$ years presenting with fever, laboratory evidence of inflammation and evidence of clinically severe illness requiring hospitalisation, with multisystem $(\geq 2)$ organ involvement (cardiac, renal, respiratory, haematologic, gastrointestinal, dermatologic or neurological AND

2. No plausible alternative diagnosis AND

3. Positive for current or recent SARS-Cov-2 infection by RT-PCR, serology or antigen test, or COVID-19 exposure within the 4 weeks prior to the onset of symptoms.

WHO case definition (11)

1. Children and adolescents $0-19$ years of age with fever $\geq 3$ days and two of the following:

- Rash or bilateral non-purulent conjunctivitis or mucocutaneous inflammation signs (oral, hands or feet).

- Hypotension or shock.

- Features of myocardial dysfunction, pericarditis, valvulitis or coronary abnormalities (including ECHO findings or elevated troponin/NT-proBNP),

- Evidence of coagulopathy (by PT, PTT, elevated D-dimers).

- Acute gastrointestinal problems (diarrhoea, vomiting or abdominal pain) AND

2. Elevated markers of inflammation such as ESR, C-reactive protein or procalcitonin AND

3. No other obvious microbial cause of inflammation, including bacterial sepsis, staphylococcal or streptococcal shock syndromes AND

4. Evidence of COVID-19 (RT-PCR, antigen or serology positive), or likely contact with patients with COVID-19. 
systems in accordance with the Office of National Statistics classification $^{(11)}$.

\section{Laboratory methods}

SARS-CoV-2 RNA was tested using semi-quantitative RT-PCR from the upper airway using combined nasopharyngeal swabs. Lower airway samples were used in the invasively ventilated children.

Antibody assay to SARS-CoV-2 spike glycoprotein was undertaken using an ELISA test.

25OHD concentrations were measured by quantitative liquid chromatography tandem Mass Spectrometry (AB Sciex API4000 MS/MS' analyser). The laboratory is subject to External Quality Assurance and meets the requirement of the UK National External Quality Assessment Service vitamin D scheme. The inter- and intra-assay CV were $<10 \%$.

\section{Body mass index}

Children with BMI centile $>98$ th were classed as obese and those between 91st and 98th were classed as overweight, in accordance with the Royal College of Paediatrics and Child Health guidelines ${ }^{(12)}$.

\section{Vitamin D status and reference 25 hydroxyvitamin $D$ concentration data}

Based on the Institute of Medicine classification ${ }^{(13)}$, 25OHD concentrations below $50 \mathrm{nmol} / \mathrm{l}(20 \mathrm{ng} / \mathrm{l})$ were classed as suboptimal. 25OHD concentrations below $30 \mathrm{nmol} / \mathrm{l}(12 \mathrm{ng} / \mathrm{l})$ were deficient, above $50 \mathrm{nmol} / \mathrm{l}$ were sufficient and 30-50 nmol/1 were insufficient.

As the children were previously fit and well with no co-morbidities, 25OHD levels were compared with healthy population means. Reference 25OHD concentrations for healthy children were obtained from the nationally representative National Diet and Nutrition Survey data ${ }^{(14-16)}$.

\section{Statistical analysis}

Descriptive statistics were used to describe the baseline characteristics and are reported as numbers (percentages), mean and standard deviation or median and range as appropriate.

A one sample $t$ test was used to compare the mean 25OHD concentrations in the study cohort to the paediatric population mean.

An independent $t$ test was used to compare normally distributed data (erythrocyte sedimentation rate and C-reactive protein) and a Mann-Whitney $U$ test to compare non-normally distributed data (25OHD concentrations) between PICU and non-PICU groups. A $P$ value below 0.05 was considered significant. All analyses were performed using SPSS statistical software v25.0 (IBM).

\section{Results}

\section{Baseline characteristics}

Eighteen children with a median (range) age of $8.9(0.3-14 \cdot 6)$ years met the case definition. The majority were males $(n 10)$.
A high proportion of the cohort was of Black, Asian and Minority Ethnic (BAME) background (89\%, 16/18). Only two children were of White British ethnicity. Obesity was noted in $31 \%(5 / 16)$ of the cohort and overweight in $31 \%(5 / 16)$.

SARS-CoV-2 IgG antibodies were positive in $94 \%(17 / 18)$ and RNA by PCR was positive in $6 \%(1 / 18)$. There were no notable co-morbidities, such as liver disease, renal disease, immunodeficiency or other conditions predisposing to recurrent infections and none were on any regular medications.

There were no deaths in the study population.

Details of the clinical characteristics and management are presented in Table 1.

\section{Vitamin D status}

Based on the Institute of Medicine classification ${ }^{(13)}$, $89 \%(16 / 18)$ had suboptimal $25 \mathrm{OHD}$ concentrations of whom $72 \%(13 / 18)$ had deficient levels and 17\% (3/18) insufficient levels. Sufficient $25 \mathrm{OHD}$ concentrations were noted in only two individuals $(11 \%, 2 / 18)$ who were both of White British ethnicity. None of the BAME children had sufficient 25OHD concentrations and $81 \%(13 / 16)$ had vitamin D deficiency. Three children ( $20 \%, 3 / 15)$ were on commercially available vitamin D supplements purchased over the counter. All children requiring PICU care had suboptimal 25OHD concentrations.

Based on the UK Scientific Advisory Committee on Nutrition recommendations where $25 \mathrm{OHD}$ levels $<25 \mathrm{nmol} / \mathrm{l}$ are considered inadequate ${ }^{(17)}$, nearly $67 \%(13 / 18)$ of the cohort were deficient.

\section{Mean 25 hydroxyvitamin D concentrations}

The mean 25OHD concentration of the whole cohort was 23.6 (sD 15.8$) \mathrm{nmol} / \mathrm{l}$. The mean $25 \mathrm{OHD}$ concentration of the BAME cohort ( $n$ 16) was 19.0 ( $\mathrm{sD} 8.8) \mathrm{nmol} / \mathrm{l}$ and the White cohort ( $n$ 2) was $60 \cdot 3(6 \cdot 6) \mathrm{nmol} / \mathrm{l}$. 25OHD below $50 \mathrm{nmol} / \mathrm{l}$ (20 ng/l) is classed as suboptimal, below $30 \mathrm{nmol} / \mathrm{l}(12 \mathrm{ng} / \mathrm{l})$ is classed as deficient and $30-50 \mathrm{nmol} / \mathrm{l}$ is insufficient.

The mean 25OHD concentrations of the whole cohort were significantly lower when compared with the 2014/2015-2015/ 2016 National Diet and Nutrition Survey mean 25OHD for children $(n$ 514, males $=276)$ aged $4-10$ years $^{(14)}(24 v .54 \mathrm{nmol} / \mathrm{l}$ (95\% CI -38.6,-19.7); $P<0 \cdot 001)$.

The mean $25 \mathrm{OHD}$ concentration in the BAME group was significantly lower when compared with the mean 25OHD in nonWhite children (4-18 years, $n$ 99/1102) from the 1997-1998 National Diet and Nutrition Survey data ${ }^{(15)}$ (19 v. $32 \mathrm{nmol} / \mathrm{l}$ (95\% CI -17.6, -8.3); $P<0.001)$.

\section{Paediatric intensive care unit v. non-paediatric intensive care unit group}

Paediatric intensive care unit group. The majority of patients presented with features of circulatory shock and required PICU care $(67 \%, 12 / 18)$ for circulatory support. All children in the PICU group required inotropes/vasopressors, $33 \%$ (4/12) required invasive ventilation and $8 \%(1 / 12)$ required hemofiltration for renal failure. None of the children required extracorporeal membrane oxygenation. The median (range) $25 \mathrm{OHD}$ concentration in the group was $18 \cdot 2(7 \cdot 8-38) \mathrm{nmol} / \mathrm{l}$. 
Table 1. Baseline characteristics, investigations and treatment of children presenting with paediatric multisystem inflammatory syndrome temporally associated with multisystem inflammatory syndrome in children (PIMS-TS)

\begin{tabular}{|c|c|c|c|c|c|c|c|c|c|c|c|c|}
\hline \multirow{2}{*}{$\begin{array}{l}\text { Decimal } \\
\text { age } \\
\text { (years) }\end{array}$} & \multirow{2}{*}{$\begin{array}{c}\text { Sex } \\
\begin{array}{c}F=\text { female } \\
M=\text { Male }\end{array} \\
\end{array}$} & \multirow[b]{2}{*}{ Ethnicity } & \multirow[b]{2}{*}{$\mathrm{BMI}^{*}$} & \multirow[b]{2}{*}{ Centile } & \multirow[b]{2}{*}{$\begin{array}{l}\text { Respiratory support IV } \dagger \\
\text { /NIV } \neq / \text { HFNC\&/O2II }\end{array}$} & \multirow[b]{2}{*}{$\begin{array}{l}\text { Treatment IVIGף, } \\
\text { MP** }^{\star *}\end{array}$} & \multirow[b]{2}{*}{$\begin{array}{l}\text { LVEF†† modified } \\
\text { Simpson's method }\end{array}$} & \multicolumn{5}{|c|}{ Laboratory results (reference values, where applicable, are provided in the footnote) } \\
\hline & & & & & & & & Sars-Cov-2 & $\begin{array}{l}25 \mathrm{OHD} \neq \ddagger \\
(\mathrm{nmol} / \mathrm{l})\end{array}$ & Bone profile§§ & $\begin{array}{l}\text { Inflammatory } \\
\text { markersIIII }\end{array}$ & Hbףी \\
\hline \multicolumn{13}{|l|}{ PICU } \\
\hline 14.5 & $\mathrm{~F}$ & $\begin{array}{l}\text { Black } \\
\text { Caribbean }\end{array}$ & 18.5 & 25th-50th) & $\mathrm{O} 2$ & IVIG, MP & $43 \%$ & $P C R-v e \lg G+v e$ & 19 & $\begin{array}{l}\text { Adj Ca 2.33 PO4 } 0.99 \\
\text { ALP } 76 \text { (50-150) }\end{array}$ & CRP 252 ESR 90 & 79 \\
\hline 9.6 & M & Asian & 20.7 & 91st-98th & HFNC, 02 & IVIG, MP & $50 \%$ & $P C R-v e \lg G+v e$ & 8.6 & $\begin{array}{l}\text { Adj Ca N/A } / \mathrm{A}^{\star * \star} \mathrm{PO} 4 \mathrm{~N} / \mathrm{A} \\
\text { ALP } 144(80-330)\end{array}$ & CRP 208 ESR 33 & 68 \\
\hline 8.8 & $\mathrm{~F}$ & $\begin{array}{l}\text { Black/African } \\
\text { Caribbean }\end{array}$ & 22.7 & 98th-99.6th & HFNC, 02 & IVIG, MP & $32 \%$ & $P C R-v e \lg G+v e$ & 7.8 & $\begin{array}{l}\text { Adj Ca } 2.40 \text { PO4 } 1.67 \\
\quad \text { ALP } 70(80-330)\end{array}$ & CRP 422 ESR 90 & 84 \\
\hline $12 \cdot 6$ & $\mathrm{~F}$ & $\begin{array}{l}\text { Black/African } \\
\text { Caribbean }\end{array}$ & $15 \cdot 2$ & 2nd-9th & None & IVIG & $42 \%$ & $P C R-v e \lg G+v e$ & 17.5 & $\begin{array}{l}\text { Adj Ca } 2.25 \text { PO4 } 1.08 \\
\text { ALP } 70 \text { (80-330) }\end{array}$ & CRP 128 ESR N/A & 94 \\
\hline $12 \cdot 7$ & M & $\begin{array}{l}\text { Mixed White/ } \\
\text { African }\end{array}$ & 19.8 & 75th-91st & $\mathrm{O} 2$ & IVIG & $38 \%$ & $P C R-v e \lg G+v e$ & 18.8 & $\begin{array}{l}\text { Adj Ca } 2.24 \text { PO4 } 0.95 \\
\text { ALP 76(90-290) }\end{array}$ & CRP 86 ESR 30 & 104 \\
\hline $5 \cdot 3$ & M & $\begin{array}{l}\text { Mixed } \\
\text { White/African }\end{array}$ & 17.9 & 91st-98th & IV, 02 & IVIG & $50 \%$ & $P C R-v e \lg G+v e$ & 16.8 & $\begin{array}{l}\text { Adj Ca } 2.32 \mathrm{PO} 41.44 \\
\text { ALP } 69(80-330)\end{array}$ & CRP 101 ESR 105 & 67 \\
\hline 10.7 & $\mathrm{~F}$ & $\begin{array}{l}\text { Black/African } \\
\text { Caribbean }\end{array}$ & $32 \cdot 3$ & $>99 \cdot 6$ th & IV, NIV, 02 & $\begin{array}{l}\text { IVIG, MP, } \\
\text { Tocilizumab }\end{array}$ & $25 \%$ & $P C R-v e \lg G+v e$ & $21 \cdot 3$ & $\begin{array}{l}\text { Adj Ca } 2.54 \text { PO4 1.34 } \\
\text { ALP } 79(80-310)\end{array}$ & CRP 480 ESR 170 & 83 \\
\hline 8 & $\mathrm{~F}$ & $\begin{array}{l}\text { Black/African } \\
\text { Caribbean }\end{array}$ & 19.9 & 91st-98th & IV & IVIG, MP, Infliximab & $48 \%$ & $P C R-v e \lg G+v e$ & 30.1 & $\begin{array}{l}\text { Adj Ca } 2.37 \mathrm{PO} 41.06 \\
\text { ALP } 95(80-330)\end{array}$ & CRP 321 ESR 42 & 75 \\
\hline 8 & $\mathrm{~F}$ & $\begin{array}{l}\text { Black/African } \\
\text { Caribbean }\end{array}$ & 14.3 & 9th-25th & None & IVIG, MP & $50 \%$ & $P C R-v e \lg G+v e$ & 27 & $\begin{array}{l}\text { Adj Ca } 2.48 \text { PO4 } 1.05 \\
\text { ALP } 120(80-330)\end{array}$ & CRP 48 ESR > 170 & 88 \\
\hline 7.1 & M & $\begin{array}{l}\text { Black/African } \\
\text { Caribbean }\end{array}$ & 23.4 & 98th-99.6th & HFNC, O2 & IVIG, Prednisolone & $42 \%$ & $P C R-v e \lg G+v e$ & 20.7 & $\begin{array}{l}\text { Adj Ca 2.30 PO4 0.8 } \\
\text { ALP } 102(80-330)\end{array}$ & CRP 264 ESR 12 & 93 \\
\hline 8.0 & M & Asian & 14.7 & 9th-25th & HFNC & None & $28 \%$ & $P C R-v e \lg G+v e$ & 38 & $\begin{array}{l}\text { Adj Ca } 2.40 \text { PO4 } 1.17 \\
\text { ALP } 59(80-330)\end{array}$ & CRP 244 ESR 45 & 79 \\
\hline $7 \cdot 0$ & M & Asian & 13.9 & 2nd-9th & IV, HFNC & None & $49 \%$ & $P C R-v e \lg G+v e$ & $13 \cdot 3$ & $\begin{array}{l}\text { Adj Ca } 2.37 \text { PO4 1.77 } \\
\text { ALP 95(80-330) }\end{array}$ & CRP 164 ESR 54 & 84 \\
\hline $\begin{array}{l}\text { Non PICU } \\
13.5\end{array}$ & $\mathrm{~F}$ & $\begin{array}{l}\text { Any other } \\
\text { White/ }\end{array}$ & $25 \cdot 6$ & 91st-98th & None & IVIG, MP & $>55 \%$ & $P C R-v e \lg G+v e$ & $12 \cdot 8$ & $\begin{array}{l}\text { Adj Ca } 2.39 \text { PO4 } 1.17 \\
\text { ALP } 93(65-240)\end{array}$ & CRP 128 ESR 70 & 83 \\
\hline 7.7 & M & Asian & 20.5 & 98th-99.6th & None & IVIG, MP & $>55 \%$ & $P C R-v e \lg G+v e$ & 14.8 & $\begin{array}{l}\text { Adj Ca 2.25 PO4 } 0.98 \\
\text { ALP 107(80-330) }\end{array}$ & CRP 138 ESR 115 & 93 \\
\hline 9.7 & M & $\begin{array}{l}\text { Mixed- White/ } \\
\text { African }\end{array}$ & $17 \cdot 9$ & 91st-98th & None & IVIG & $>55 \%$ & $P C R+v e \lg G+v e$ & 32.8 & $\begin{array}{l}\text { Adj Ca } 2.33 \text { PO4 } 1.19 \\
\text { ALP } 91(80-330)\end{array}$ & CRP 42 ESR 75 & 76 \\
\hline 0.6 & $\mathrm{~F}$ & White & $\begin{array}{c}\text { Not } \\
\text { available }\end{array}$ & & None & IVIG & $>55 \%$ & $P C R$-ve lgG -ve & 55.6 & $\begin{array}{l}\text { Adj Ca } 2.74 \text { PO4 1.77 } \\
\text { ALP } 148(80-330)\end{array}$ & CRP 92 ESR 82 & 89 \\
\hline $13 \cdot 2$ & M & White & 27.5 & 98th-99.6th & None & None & $>55 \%$ & $P C R-v e \lg G+v e$ & 65 & $\begin{array}{l}\text { Adj Ca } 2.48 \text { PO4 1.72 } \\
\text { ALP } 106(90-290)\end{array}$ & CRP 152 ESR 60 & 136 \\
\hline 0.29 & M & $\begin{array}{r}\text { Black/African } \\
\text { Caribbean }\end{array}$ & $\begin{array}{c}\text { Not } \\
\text { available }\end{array}$ & & None & None & $>55 \%$ & $P C R-v e \lg G+v e$ & 10.6 & $\begin{array}{l}\text { Adj Ca } 2.48 \text { PO4 1.29 } \\
\text { ALP } 403(80-330)\end{array}$ & CRP 58 ESR 5 & 82 \\
\hline
\end{tabular}

PICU, paediatric intensive care unit; 25OHD, 25 hydroxyvitamin D; CRP, C-reactive protein; LVEF, left ventricular ejection fraction.

* BMI centile, RCPCH chart (<2nd centile low BMI, > 91st overweight, > 98th obese, > 99.6th severely obese).

† Invasive ventilation.

$\S$ High flow nasal cannula oxygen.

II Supplemental oxygen

II Intravenous Ig.

** Methylprednisolone.

†† Left ventricular ejection fraction (mild impairment $45-54 \%$, moderate $30-44 \%$ and severe $<30 \%$ ).

¥ 25-hydroxyvitamin D (deficiency $<30 \mathrm{nmol} / /$, insufficiency $30-50 \mathrm{nmol} / /$, sufficiency $>50 \mathrm{nmol} / \mathrm{l}$ ).

$\S \S$ Adjusted $\mathrm{Ca}$ (normal range 2:20-2.70 mmo///), phosphate 1.30-2.40 mmo///, alkaline phosphatase (age- and sex-specific ranges provided in the table).

IIII C-reactive protein (normal range 0-10 $\mathrm{mg} / \mathrm{l})$, erythrocyte sedimentation rate (normal range $0-9 \mathrm{~mm} / \mathrm{h}$ ).

१ๆ $\mathrm{Hb}$ (reference range: 3 months-4 years: $110-140 \mathrm{~g} / \mathrm{l}, 5-12$ years: $115-140 \mathrm{~g} / \mathrm{l})$. 
All except two patients had vitamin D deficiency $(25 \mathrm{OHD}<30$ $\mathrm{nmol} / \mathrm{l})$. The median (range) C-reactive protein was 226 (48480) $\mathrm{mg} / \mathrm{l}$ and erythrocyte sedimentation rate was 54 (12-170) $\mathrm{mm} / \mathrm{h}$.

Non-paediatric intensive care unit group. Approximately, a third of the study cohort $(33 \%, 6 / 18)$ presented with milder disease features and did not require admission to PICU. The median (range) 25OHD concentration in the group was 23.5 (10.6-65.0) $\mathrm{nmol} / \mathrm{l}$. The median (range) C-reactive protein and erythrocyte sedimentation rate were $110(42-152) \mathrm{mg} / \mathrm{l}$ and $67 \cdot 8(5-115)$ $\mathrm{mm} / \mathrm{h}$, respectively. There was no mortality in either group.

Investigations and management of PICU group $v$. non-PICU group are presented in Table 2 .
When compared with the non-PICU group, the PICU group had lower mean 25OHD concentrations (Fig. 1) (31 (sD 23.8) v. $19.5(\mathrm{sD} 8.8) \mathrm{nmol} / \mathrm{l}$, respectively; $P=0.5$ ) but this was not statistically significant. The mean C-reactive protein in the PICU group was significantly higher than that in the non-PICU group (228.5 (SD 131.0) v. 101.7(SD 45.0) $\mathrm{mg} / \mathrm{l}$, respectively; $P=0.03)$. The erythrocyte sedimentation rate in the PICU and non-PICU groups did not differ significantly (76.5 (SD 54.4) $v$. $67 \cdot 8(\mathrm{sD} 36 \cdot 0) \mathrm{mm} / \mathrm{h}$, respectively; $P=0 \cdot 70)$.

\section{Cardiac function}

All PICU patients had abnormal ( $<55 \%$ ) left ventricular ejection fraction based on modified Simpson's method. Severe

Table 2. Investigations and management of PICU group v. non-PICU group

\begin{tabular}{|c|c|c|c|c|c|}
\hline & \multicolumn{2}{|c|}{ PICU } & \multicolumn{3}{|c|}{ Non-PICU } \\
\hline & $n$ & $\%$ & $n$ & & $\%$ \\
\hline \multicolumn{6}{|l|}{$25 \mathrm{OHD}^{\star}$} \\
\hline Median & \multirow{2}{*}{\multicolumn{2}{|c|}{$\begin{array}{c}18 \cdot 2 \\
7 \cdot 8-38\end{array}$}} & \multirow{2}{*}{\multicolumn{3}{|c|}{$\begin{array}{c}23 \cdot 5 \\
10 \cdot 6-65\end{array}$}} \\
\hline Range & & & & & \\
\hline \multicolumn{6}{|l|}{ CRPt } \\
\hline Median & \multirow{2}{*}{\multicolumn{2}{|c|}{$\begin{array}{c}226 \\
48-480\end{array}$}} & \multirow{2}{*}{\multicolumn{3}{|c|}{$\begin{array}{c}110 \\
42-152\end{array}$}} \\
\hline Range & & & & & \\
\hline \multicolumn{6}{|l|}{ ESR $\ddagger$} \\
\hline Median & \multirow{2}{*}{\multicolumn{2}{|c|}{$\begin{array}{c}54 \\
12-170\end{array}$}} & \multirow{2}{*}{\multicolumn{3}{|c|}{$\begin{array}{c}67 \cdot 8 \\
5-115\end{array}$}} \\
\hline Range & & & & & \\
\hline Inotropes/vasopressors & 12 & 100 & 0 & & 0 \\
\hline Invasive ventilation & 4 & 33 & 0 & & 0 \\
\hline Hemofiltration & 1 & 8 & 0 & & 0 \\
\hline LVEF§ normal & 0 & 0 & 3 & & 50 \\
\hline LVEF mild impairment & 4 & 34 & 3 & & 50 \\
\hline LVEF moderate impairment & 6 & 50 & & & 0 \\
\hline LVEF severe impairment & 2 & 16 & & & 0 \\
\hline
\end{tabular}

PICU, paediatric intensive care unit; 25OHD, 25 hydroxyvitamin D; CRP, C-reactive protein; ESR, erythrocyte sedimentation rate; LVEF, left ventricular ejection fraction.

* 25-hydroxyvitamin $D$ (deficiency < 30nmol/l, insufficiency $30-50 \mathrm{nmol} / \mathrm{l}$, sufficiency $>50 \mathrm{nmol} / \mathrm{l}$ ).

†C-reactive protein (normal range $0-10 \mathrm{mg} / \mathrm{l})$.

‡ Erythrocyte sedimentation rate (normal range 0-9 mm/h).

$\S$ Left ventricular ejection fraction (mild impairment $45-54 \%$, moderate $30-44 \%$ and severe $<30 \%$ ).

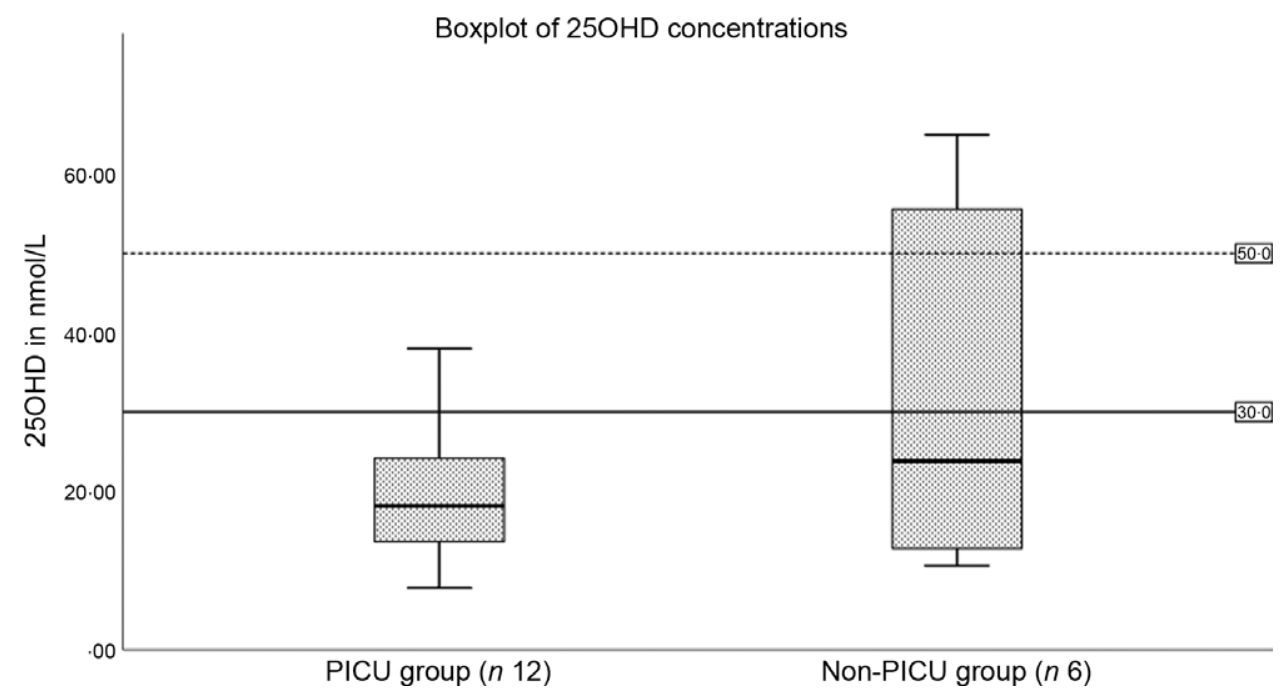

Fig. 1. 25 hydroxyvitamin $\mathrm{D}(25 \mathrm{OHD})$ concentrations in paediatric intensive care unit $(\mathrm{PICU})$ and non-PICU groups $(P=0 \cdot 11)$. 
impairment was recorded in $16 \%(2 / 12), 50 \%(6 / 12)$ had moderate impairment and $34 \%(4 / 12)$ mild impairment.

In the non-PICU group, $50 \%$ (3/6) had normal left ventricular ejection fraction and it was mildly impaired in $50 \%(3 / 6)$.

Echocardiogram in children with suboptimal 25OHD (16/18) showed normal coronaries in $31 \%(n 5)$, prominent coronaries in $63 \%(n 10)$ and fusiform dilatation in $6 \%(n 1)$. Children with sufficient $25 \mathrm{OHD}$ levels (2/18) had normal coronaries and left ventricular ejection fraction and did not require PICU admission.

\section{Discussion}

This is the first report detailing the vitamin D status of children with PIMS-TS requiring hospitalisation, highlighting the alarmingly high proportion of deficiency. PIMS-TS was predominant in children of BAME origin, with $81 \%$ being vitamin D deficient. A high proportion of the whole cohort $(72 \%)$ and specifically PICU cohort (83\%) were vitamin D deficient. Children with PIMS-TS had significantly lower mean $25 \mathrm{OHD}$ concentrations compared with the nationally representative healthy White British and BAME children; however, there was no association with disease severity.

Suboptimal vitamin D status has been reported in around $50 \%$ of critically ill children in a previous systematic review and meta-analysis ${ }^{(18)}$. We, however, noted suboptimal 25OHD levels in $100 \%$ of our PICU group, probably due to the higher proportion of BAME individuals. The limited National Diet and Nutrition Survey data on BAME individuals in the UK also report a higher proportion of vitamin D deficiency $(42.9 \% ; n 63)$ in comparison with White children $(15.0 \%, n 448)^{(16)}$. It is noteworthy that all children of BAME origin with PIMS-TS had suboptimal vitamin D status. A higher prevalence of PIMS-TS with disproportionate number of intensive care admissions of children from BAME background has been reported in the $\mathrm{UK}^{(5,19)}$ Similarly, hypocalcaemic complications of vitamin D deficiency ${ }^{(20)}$, including nutritional rickets $^{(21)}$, are also 90-166-fold higher in UK Black and Asian children when compared with their White counterparts ${ }^{(22)}$.

The increased risk of acute viral respiratory infections with vitamin D deficiency and the potential protective effects of supplementation has been extensively reported ${ }^{(23)}$. Nonetheless, currently there remains insufficient evidence to recommend routine supplementation to prevent acute respiratory tract infections $^{(24)}$ or COVID-19(9). Evidence on the link between 25OHD status and SARS-CoV-2 continues to emerge, with suggestion of an inverse relationship between circulating 25OHD levels and SARS-CoV-2 positivity ${ }^{(25)}$. The relevance of vitamin $\mathrm{D}$ as a modifiable risk factor in severe PIMS-TS due to its actions on unregulated cytokine response requires further consideration. Consistent evidence of PIMS-TS being mediated by amplified inflammatory responses to SARS-CoV-2 and the regulatory actions of $25 \mathrm{OHD}$ on pro-inflammatory cytokine signalling further substantiates the possible role of 25OHD in PIMS-TS. This hypothesis is strengthened by the association of low 25OHD with Kawasaki's disease ${ }^{(26)}$, a childhood inflammatory disease with which PIMS-TS shares considerable overlap ${ }^{(27)}$. 25OHD levels in Kawasaki's disease have previously been linked to coronary outcomes which may be of relevance in children affected with PIMS-TS ${ }^{(26)}$. Given that nearly $14 \%$ of the UK population are of BAME origin and are at a high risk of vitamin D deficiency ${ }^{(28)}$, ongoing evaluation of the putative link between ethnicity, severe COVID-19 and vitamin D deficiency is essential. Randomised controlled trials in the community would be required to establish a causative link between vitamin D deficiency and COVID-19.

There was no link between 25OHD concentrations and disease severity in our cohort, but our study was not adequately powered to evaluate such a relationship. There is currently insufficient evidence to recommend vitamin $\mathrm{D}$ for prevention or treatment of COVID-19 or related conditions. Nonetheless, the finding of widespread deficiency in the BAME population cannot be disregarded. Suboptimal vitamin D status in UK residents ${ }^{(29)}$, especially its BAME residents, is a long-standing problem $^{(28,30)}$ which warrants intervention. Older children and adolescents where there is a higher prevalence of severe COVID-19 and PIMS-TS are also reported to be at a higher risk of vitamin D deficiency ${ }^{(15,16)}$. A number of factors need addressing to improve the vitamin D status of the UK population. Firstly, the threshold for sufficiency in the UK is set as $\geq 25 \mathrm{nmol} / \mathrm{l}^{(17)}$, whereas other institutes ${ }^{(13)}$ and consensus guidance ${ }^{(31)}$ regard levels $>50 \mathrm{nmol} / \mathrm{l}$ as sufficiency and $<30 \mathrm{nmol} / \mathrm{l}$ as deficiency. Secondly, the recommended vitamin $\mathrm{D}$ requirement for children $>1$ year in the UK is lower ( $10 \mu \mathrm{g}$ or 400 IU daily) than that supported by other evidence-based guidance $(15 \mu \mathrm{g}$ or 600 IU daily $)^{(13,31)}$. Thirdly, less than a third of this lower recommended intake is met through diet in UK children ${ }^{(29)}$ due to the lack of widespread mandatory food fortification ${ }^{(28,32)}$. Last but not the least, the uptake of vitamin D supplements in UK infants and children is also very low at $<20 \%{ }^{(33)}$ due to poor policy implementation ${ }^{(34)}$. Hence, the UK has a higher prevalence of vitamin D deficiency compared with other countries at comparable latitude with similar proportions of BAME population ${ }^{(16)}$. Robust vitamin D supplementation of all high-risk groups has no notable side effects and is a safe option irrespective of the link. At-risk individuals should be reminded of the need for supplementation at each healthcare contact ${ }^{(34)}$.

Our study was limited by the small sample size given the rarity of the condition. Nonetheless, the data provided are of paramount public health importance. The chronicity of vitamin $\mathrm{D}$ deficiency was not known due to the unavailability of parathyroid hormone levels and the concurrent presence of hypophosphatasemia related to the acute insult ${ }^{(35)}$. However, the prevalence of deficiency reported here mirrors data from other studies of predominantly BAME populations ${ }^{(36,37)}$, yet again highlighting the importance of supplementing high-risk individuals and adoption of long-term strategies such as food fortification, as a cost-effective way of optimising population vitamin D status $^{(38)}$.

\section{Conclusions}

PIMS-TS has seen an over-representation of children from BAME background, who are also at greatest risk of vitamin D deficiency. In view of the high prevalence of vitamin D deficiency in our PIMS-TS cohort, we call for mandated, yearround vitamin D supplementation of all high-risk children and 
adolescents. Food fortification with vitamin D should be strongly considered as a long-term strategy.

\section{Acknowledgements}

We would like to acknowledge the support of the Birmingham Women's and Children's NHS Foundation trust staff, including Drs Fiona Reynolds, Ian Wacogne, Jeremy Kirk, Jim Gray, Mitul Patel, Sarah Heap, Phillip Hurley, Sakeena Samar, Maria Lazarou, Tristan Ramcharan, Penny Davis, Kathryn Harrison, William Coles, Pam Dawson, Sean Monaghan, Deevena Chinthala, Professor Alex G Richter (Department of Immunology, University of Birmingham), Dhruv Parekh (Consultant in intensive care, UHB \& BACR, University of Birmingham) and colleagues in paediatric departments in the West Midlands.

This work did not receive any specific funds. S. U. is supported by Global Challenges research scholarship, University of Birmingham, and B. R. S. is supported by a Clinician Scientist fellowship programme, National Institute of Health Research. The other authors received no external funding for this manuscript. The authors have no financial relationships relevant to this article to disclose.

D. J. and S. U.: conception, study design, data analysis, tables, revisions and approval of final manuscript. A. D.: data collection, tables, first draft. M. O., K. M., S. H. A.: data collection, analysis, literature search, tables, revisions. H. K., A. C., E. A.-A., S. W., S. H., B. R. S.: data collection, analysis, review, revisions.

The authors have no conflicts of interest relevant to this article to disclose.

\section{References}

1. Ludvigsson JF (2020) Systematic review of COVID-19 in children shows milder cases and a better prognosis than adults. Acta Paediatr 109, 1088-1095.

2. Kanthimathinathan HK, Dhesi A, Hartshorn S, et al. (2020) COVID-19: a UK children's hospital experience. Hosp Pediatr 10, 802-805.

3. Royal College of Paediatrics and Child Health (2020) Guidance - Paediatric multisystem inflammatory syndrome temporally associated with COVID-19 (PIMS). https://www. rcpch.ac.uk/resources/guidance-paediatric-multisysteminflammatory-syndrome-temporally-associated-covid-19-pims (accessed June 2021).

4. Centers for Disease Control and Prevention (2020) Multisystem Inflammatory Syndrome in Children (MIS-C) Associated with Coronavirus Disease 2019 (COVID-19). https://emergency. cdc.gov/han/2020/han00432.asp (accessed June 2021).

5. Whittaker E, Bamford A, Kenny J, et al. (2020) Clinical characteristics of 58 children with a pediatric inflammatory multisystem syndrome temporally associated with SARS-CoV-2. J Am Med Assoc 324, 259-269.

6. Lee PY, Day-Lewis M, Henderson LA, et al. (2020) Distinct clinical and immunological features of SARS-COV-2-induced multisystem inflammatory syndrome in children. J Clin Invest 130, 5942-5950.

7. Panfili FM, Roversi M, D'Argenio P, et al. (2021) Possible role of vitamin D in Covid-19 infection in pediatric population. J Endocrinol Invest 44, 27-35.
8. Daneshkhah A, Agrawal V, Eshein A, et al.. (2020) Evidence for possible association of vitamin $\mathrm{D}$ status with cytokine storm and unregulated inflammation in COVID-19 patients. Aging Clin Exp Res 32, 2141-2158. doi: 10.1007/s40520-020-01677-y. Epub 2020 Sep 2. PMID: 32876941; PMCID: PMC7465887.

9. National Institute for Health and care excellence (2020) COVID-19 Rapid Evidence Summary: Vitamin D for COVID-19 [ES28]. https://www.nice.org.uk/advice/es28/chapter/ Key-messages (accessed June 2021).

10. World Health Organisation (2020) Multisystem inflammatory syndrome in children and adolescents with COVID-19. https:// www.who.int/publications/i/item/multisystem-inflammatorysyndrome-in-children-and-adolescents-with-covid-19 (accessed June 2021).

11. Office for national statistics (2011) Ethnicity in England and Wales. https://www.ons.gov.uk/peoplepopulationandcommunity/ culturalidentity/ethnicity/articles/ethnicityandnationalidentityin englandandwales/2012-12 (accessed June 2021).

12. Royal College of Paediatrics and Child Health (2020) BMI Chart - RCPCH. https://www.rcpch.ac.uk/resources/body-massindex-bmi (accessed June 2021).

13. Ross AC, Manson JAE, Abrams SA, et al. (2011) The 2011 report on dietary reference intakes for calcium and vitamin $\mathrm{D}$ from the Institute of Medicine: What clinicians need to know. J Clin Endocrinol Metab 9, 53-58.

14. Public Health England (2018) Results of the National Diet and Nutrition Survey (NDNS) Rolling Programme for 2014 to 2015 and 2015 to 2016. https://www.gov.uk/government/statistics/ ndns-results-from-years-7-and-8-combined (accessed June 2021).

15. Absoud M, Cummins C, Lim MJ, et al. (2011) Prevalence and predictors of vitamin D insufficiency in children: A great Britain population based study. PLoS One 6, 6-11.

16. Cashman KD (2016) Dowling KG. Vitamin D deficiency in Europe: pandemic? Am J Clin Nutr 103, 1033-1044.

17. Scientific Advisory Committee on Nutrition (2016) Vitamin D and Health 2016. https://assets.publishing.service.gov.uk/ government/uploads/system/uploads/attachment_data/file/ 537616/SACN_Vitamin_D_and_Health_report.pdf (accessed June 2021).

18. McNally JD, Nama N, O'Hearn K, et al. (2017) Vitamin D deficiency in critically ill children: A systematic review and meta-analysis. Crit Care 21, 1-13.

19. Davies P, Evans C, Kanthimathinathan HK, et al. (2020) Intensive care admissions of children with paediatric inflammatory multisystem syndrome temporally associated with SARSCoV-2 (PIMS-TS) in the UK: a multicentre observational study. Lancet Child Adolesc Heal 4, 669-677.

20. Basatemur E \& Sutcliffe A (2015) Incidence of hypocalcemic seizures due to vitamin $\mathrm{D}$ deficiency in children in the United Kingdom and Ireland. J Clin Endocrinol Metab 100, E91-E95.

21. Julies P, Lynn RM, Pall K, et al. (2020) Nutritional rickets under 16 years : UK surveillance results. Arch Dis Child 105, $587-592$.

22. Uday $S$ \& Högler W (2020) Response letter to Nutritional rickets under 16 years: UK surveillance results. Archives of Disease in Childhood. https://adc.bmj.com/content/105/6/587.responses\# response-letter-to-nutritional-rickets-under-16-years-uksurveillance-results (accessed June 2021).

23. Martineau AR, Jolliffe DA, Hooper RL, et al. (2017) Vitamin D supplementation to prevent acute respiratory tract infections: systematic review and meta-analysis of individual participant data. Br Med J 356, i6583.

24. Scientific Advisory Committee on Nutrition (2020) Rapid Review: vitamin D and Acute Respiratory Tract Infections. https://app.box.com/s/g0ldpth1upfd7fw763ew3aqa3c0pyvky (accessed June 2021). 
25. Kaufman HW, Niles JK, Kroll MH, et al. (2020) SARS-CoV-2 positivity rates associated with circulating 25 -hydroxyvitamin D levels. PLoS One 15, e0239252.

26. Stagi S, Rigante D, Lepri G, et al. (2015) Severe vitamin D deficiency in patients with Kawasaki disease: a potential role in the risk to develop heart vascular abnormalities? Clin Rheumatol 35, 1865-1872.

27. Brown RA (2020) Rapid response to: is ethnicity linked to incidence or outcomes of covid-19? BAME children at high risk of PIMS-TS, a Covid-19 Kawasaki-like disease - vitamin D, a factor? - testing and data urgently required. Br Med J 369, m1548.

28. Uday S \& Högler W (2018) Prevention of rickets and osteomalacia in the UK: political action overdue. Arch Dis Child 103, 901-906.

29. Bates B, Lennox A, Prentice A, et al. (2014) National Diet, Nutrition Survey: Results from Years 1, 2, 3, 4 (combined) of the Rolling Programme. https://www.gov.uk/government/ statistics/national-diet-and-nutrition-survey-results-from-years-1to-4-combined-of-the-rolling-programme-for-2008-and-2009to-2011-and-2012 (accessed June 2021).

30. Bivins R (2007) 'The English Disease' or 'Asian Rickets'? medical responses to postcolonial immigration. Bull Hist Med 81, 533-568.
31. Munns CF, Shaw N, Kiely M, et al. (2016) Global consensus recommendations on prevention and management of nutritional rickets. Horm Res Paediatr 85, 83-106.

32. Aguiar M, Andronis L, Pallan M, et al. (2017) Preventing vitamin D deficiency (VDD): a systematic review of economic evaluations. Eur J Public Health 27, 292-301.

33. Jessiman T, Cameron A, Wiggins M, et al. (2013) A qualitative study of uptake of free vitamins in England. Arch Dis Child $\mathbf{9 8}$, 587-591.

34. Uday S, Kongjonaj A, Aguiar M, et al. (2017) Variations in infant and childhood Vitamin D supplementation programs across Europe and factors influencing adherence. Endocr Connect 6, 667-675.

35. McKiernan FE, Shrestha LK, Berg RL, et al. (2014) Acute hypophosphatasemia. Osteoporos Int 25, 519-523.

36. Das G, Crocombe S, McGrath M, et al. (2006) Hypovitaminosis D among healthy adolescent girls attending an inner city school. Arch Dis Child 91, 569-572.

37. Darling AL, Hart KH, MacDonald HM, et al. (2013) Vitamin D deficiency in UK South Asian Women of childbearing age: a comparative longitudinal investigation with UK Caucasian women. Osteoporos Int 24, 477-488.

38. Aguiar M, Andronis L, Pallan M, et al. (2019) The economic case for prevention of population vitamin D deficiency: a modelling study using data from England and Wales. Eur J Clin Nutr 74, 825-833. 